\title{
THE GENETICS OF BREVISTYLIS IN CENOTHERA*
}

\author{
D. G. CATCHESIDE \\ Department of Genetics, University of Adelaide, Waite Agricultural \\ Research Institute
}

Received 20.iv.53

\section{INTRODUCTION}

THE mutant brevistylis, which differs from the normal in its short style and deformed stigma lobes, is one of the classic recessive mutations found by de Vries (IgoI-03) in O. Lamarckiana and shown by him to have a simple Mendelian inheritance. The gene is exceptional in showing segregation independently of either gametic complex in all Enothera complex interchange heterozygotes in which it has been studied (Renner, I942). This independence is shown particularly in a combination, such as jugens. br gaudens (Emerson and Sturtevant, 1932) which has a ring of 14 chromosomes at metaphase I of meiosis. Other combinations, in which $b r$ segregates independently of the complexes, are albicans. velans, gaudens. flectens and rubens. flectens, each with a ring of 14 chromosomes, and albicans. gaudens with a ring of 8 and a ring of 6 chromosomes (Renner, 1942). Hence, like the genes governing flower size, it must be at a locus genetically remote from those genes, or blocks of genes, which characterise the various complexes. Indeed there is evidence (Emerson and Sturtevant, I932) of linkage of brevistylis to the flower size genes, with about 15 per cent. recombination. The demonstration of its position cytogenetically with considerable precision is therefore of more than trivial interest.

In the original stock, which was obtained from Prof. G. H. Shull in $1935, O$. Lamarckiana brevistylis was, as de Vries originally found, completely female sterile owing to the extreme deformation of the stigma lobes, upon which pollen failed to germinate. The gene was transferred from this stock to the structurally homozygous $O$. blandina, by using pollen of $O$. Lamarckiana brevistylis on $O$. blandina stigmas. Amongst the progeny, which consisted of 52 velans. hblandina and 3 gaudens. 'blandina plants, the gaudens. hblandina combination heterozygous for the $b r$ gene was selfed. The velans. hblandina combination is unsuitable to use as it is difficult to rid the progeny of heritable chloroplast defects. The progeny from the selfing of $b r$ gaudens. $b r^{+}$ bblandina consisted of I blandina plant that was brevistylis and 40 blandina and $4{ }^{h}$ blandina. gaudens plants that were not. Surprisingly the blandina plant homozygous for $b r$ was female fertile and all descendant stocks have also been female fertile.

The blandina brevistylis strain shows the short style effect very

* Dedicated to Otto Renner on his seventieth birthday. 
clearly even in very young buds, the stigma lobes being at the mouth of the hypanthium or a little higher, but definitely below the level of the stamens. The stigmas in this strain are only slightly different from normal plants. It is possible that 0 . Lamarckiana contains genes which operate to make brevistylis more deleterious, but no direct test by returning the gene to 0 . Lamarckiana stock has been attempted.

Besides the stylar effects of the gene, which can be recognised in very young buds, the mature flower buds have a more stumpy appearance and the sepal tips are distinctly shorter and relatively thicker and are not appressed to one another as are those of normal buds. Further, the leaves of brevistylis plants are usually relatively broader and blunter, but this character is not a completely reliable one to employ in scoring families, where other characters are also segregating.

Identification of the chromosome bearing the brevistylis locus has been attempted by making trisomics heterozygous for $b r$ and searching for trisomic ratios in the backcross progeny. As the trisomics of $O$. blandina have not been described hitherto it is desirable to give first a brief account of them and of how their extra chromosomes have been identified.

\section{THE TRISOMICS OF O. BLANDINA}

\section{(a) Primary}

The seven chromosomes of $O$. blandina have been identified, in terms of defined standard interchanges, as $1 \cdot 2,3.4,5.6,7 \cdot 10,8 \cdot 13$, 9.14 and II I2 (Catcheside, 1940). All of the seven primary trisomics are known and each may be recognised phenotypically with very little trouble. Each is referred to by a distinctive nickname which recalls its most prominent diagnostic character. The descriptions indicate the features by which the trisomics differ from the diploid. Egg transmission is expressed as the percentage of the progeny of a trisomic, pollinated by a diploid, which are trisomic.

I. Lanceolate, trisomic for chromosome $\mathrm{I} \cdot 2$, is somewhat shorter, with more numerous, smooth, deeper green, lance-shaped leaves, generally more crowded on the stem than in the diploid. The buds appear polished and deeper red. The flowers are small, the anthers thin and the stigma lobes short, thick and often imperfectly divided from one another. Egg transmission i I per cent.

2. Whitish, trisomic for chromosome 3.4 , is a dwarf and weak plant with small elliptical leaves, which are rugose, white margined and flecked with numerous areas of tissue, white or yellow, that are defective in chlorophyll development. The bracts are short, relatively broad and patent. The buds are shorter and more slender and the sepal tips shorter and pink-tipped. Being so feeble, it breeds poorly and is difficult to maintain. Egg transmission 6 per cent.

3. Broad, trisomic for chromosome $5 \cdot 6$, has a strongly biennial tendency. The leaves are brighter green, very broad and blunt at the apex. They are strongly crinkled. The buds are stout, blunt and green. The petals are rather fleshy and often cleft at the sides. The stigma lobes are very stout. It is completely male sterile, the anthers being gnarled and indehiscent. Thus it is very similar in general 
character to 0 . Lamarckiana lata in which chromosome 5.6 is also the extra one (Catcheside, I937). Egg transmission I 4 per cent.

4. Linear, trisomic for $7 \cdot 10$, has very long and extremely narrow rosette leaves, which are somewhat red margined. The leaves become shorter up the stem, passing into the linear, patent, nearly flat bracts. The buds are deeper red and are covered with a short pubescence. The flowers are smaller in all their parts. Egg transmission $\mathrm{I} 2$ per cent.

5. Glossy, trisomic for $8 \cdot \mathrm{I}_{3}$ or $9 \cdot \mathrm{I}_{4}$, is a slender, little branched plant, generally lacking basal branches. The leaves are short and somewhat wavy, and their upper surface has a high gloss at certain stages of growth. The stigma lobes are shorter and more slender and are borne at the level of the anthers. Egg transmission 28 per cent.

6. Blunt, trisomic for $9 \cdot \mathrm{I}_{4}$ or $8 \cdot \mathrm{I}_{3}$, has blunt spathulate leaves which are relatively broad for their length. The stigma lobes are relatively thick and large. Resembles " broad", but is maie fertile. Egg transmission 29 per cent.

7. Golden, trisomic for $11 \cdot 12$, has leaves which tend to be virescent, each leaf in development passing through a juvenile stage when it is golden yellow and then very slowly becoming green beginning from the apex and margins. The leaves are also relatively broader and shorter and strongly crinkled. The plants are slower in growing to maturity. Egg transmission 13 per cent.

The evidence identifying the extra chromosomes in the respective trisomics is as follows. The disomic gametes have been combined with various standard interchange complexes, and the trisomics examined cytologically. The complexes used were :-

\begin{tabular}{|c|c|c|c|c|c|c|c|c|c|}
\hline${ }^{h}$ blandina & - & . & I $\cdot 2$ & $3 \cdot 4$ & $5 \cdot 6$ & $7 \cdot 10$ & $8 \cdot 13$ & $9^{9} \cdot 14$ & II I I 2 \\
\hline blandina-A & . & - & $I \cdot 2$ & $3 \cdot$ I I & $4^{\cdot 12}$ & $5^{\cdot 6}$ & $7 \cdot 10$ & $8 \cdot 13$ & $9^{\cdot} \mathrm{I} 4$ \\
\hline blandina-B & . & • & $I \cdot 4$ & $2 \cdot 3$ & $5 \cdot 6$ & $7 \cdot 10$ & $8 \cdot 13$ & $9 \cdot 14$ & $\mathrm{II} \cdot \mathrm{I} 2$ \\
\hline rubricalyx $\alpha$ & • & $\cdot$ & $I \cdot 2$ & 3.4 & $5^{\cdot 6}$ & $7 \cdot 14$ & $8 \cdot 13$ & $9 \cdot 10$ & $\mathrm{II} \cdot \mathrm{I} 2$ \\
\hline${ }^{n}$ Hookeri & $\theta^{\circ}$ & $\cdot$ & $I \cdot 2$ & $3 \cdot 4$ & $5 \cdot 6$ & $7 \cdot 8$ & $9 \cdot$ io & II $\cdot 12$ & I3. I4 \\
\hline flavens & - & 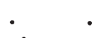 & $1 \cdot 4$ & 2.3 & $5 \cdot 6$ & $7 \cdot 8$ & $9 \cdot$ ro & $I I \cdot I 2$ & $13 \cdot 14$ \\
\hline $\begin{array}{l}\text { hpurpurata } \\
\text { or "pale }\end{array}$ & $\begin{array}{l}{ }^{h} f r \\
\text { bla }\end{array}$ & $\begin{array}{l}\text { nciscana, } \\
\text { dina) }\end{array}$ & $1 \cdot 2$ & $3 \cdot 4$ & $5 \cdot 6$ & $7 \cdot 10$ & $8 \cdot 9$ & II $\cdot 12$ & $13 \cdot 14$ \\
\hline velans & & . & $I \cdot 2$ & 3. & $5^{\cdot 8}$ & $6 \cdot 7$ & 9.10 & II $\cdot 12$ & I $3 \cdot 14$ \\
\hline rubens (or $g$ & udens) & & $1 \cdot 2$ & $3 \cdot 11$ & $4 \cdot 9$ & $5^{\cdot 6}$ & $7 \cdot 12$ & $8 \cdot 14$ & IO $\cdot 13$ \\
\hline
\end{tabular}

The chromosome associations in the trisomics are written with the extra chromosome attached to the configuration containing the chromosome homologous to it. Thus $2+r$ means it is a member of a trivalent, $4+\mathrm{r}$ that it is similar to one of the chromosomes in an interchange quadrivalent.

$\begin{array}{cl}\text { Lanceolate_-_blandina. } & \text { blandina-B } \\ , & \text { blandina-A } \\ " & \text { rubricalyx- } \alpha \\ " & \text { "Hookeri } \\ " & \text { flavens } \\ & \text { hpurpurata } \\ & \text { velans }\end{array}$

$\begin{array}{llllll}4+1, & 2, & 2, & 2, & 2, & 2 \\ 2+1, & 4, & 2, & 2, & 2, & 2 \\ 2+1, & 4, & 2, & 2, & 2, & 2 \\ 2+1, & 6, & 2, & 2, & 2 & \\ 4+1, & 6, & 2, & 2 & & \\ 2+1, & 4, & 2, & 2, & 2, & 2 \\ 2+1, & 8, & 2, & 2 & & \end{array}$

The lanceolate chromosome is one of the two by which ${ }^{b}$ blandina differs from blandina- $B$, namely $1 \cdot 2$ or 3.4 . It is not one of the chromosomes, 3.4 and $\mathrm{I} \times 12$, by which hblandina differs from blandina-A, and so must be $1 \cdot 2$. The other observations agree with this.

Whitish-blandina-B. velans $4+\mathrm{I}, 8,2$ 
The whitish chromosome is therefore $\mathrm{I} \cdot 2$ or $3 \cdot 4$, and so must be 3.4 since $I \cdot 2$ is the extra chromosome in lanceolate.

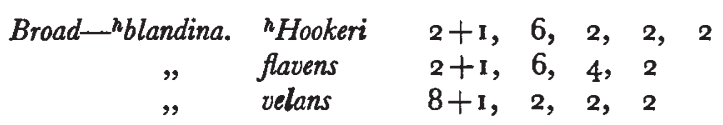

The broad chromosome is one of those which hblandina and flavens have in common, i.e. 5.6 and II.I2, and is one of those by which bblandina differs from velans, i.e. $5 \cdot 6,7 \cdot 10,8 \cdot 13,9^{\cdot} \cdot 14$. Only $5 \cdot 6$ is common to these possibilities.

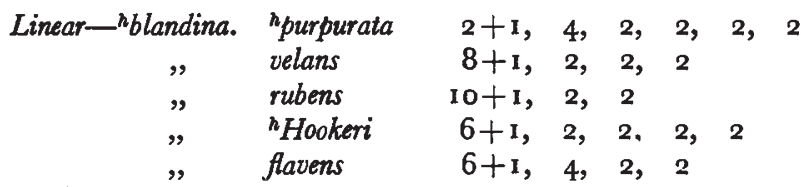

The linear chromosome is not 8.13 or 9.14 from the combination with hurpurata, is not $\mathrm{I} \cdot 2,3.4$ or $\mathrm{I} \mathrm{I} \cdot \mathrm{I} 2$ from the combination with velans and is not $\mathrm{I} \cdot 2$ or $5 \cdot 6$ from the combination with rubens. This leaves only $7 \cdot 10$, which satisfies all the observations.

$$
\begin{aligned}
& \text { Glossy-hblandina. 'npurpurata } 4+\mathbf{1}, \quad 2, \quad 2, \quad 2, \quad 2, \quad 2 \\
& \text { " flavens } 6+1,4,2,2
\end{aligned}
$$

The glossy chromosome is one of the two by which hblandina differs from ${ }^{h}$ purpurata, namely $8 \cdot 13$ or $9 \cdot \mathrm{I} 4$.

$$
\begin{aligned}
& \text { Blunt-hblandina. blandina-A } 2+1,4,2,2,2,2 \\
& \text { " "pale" blandina } 4+1,2,2, \quad 2, \quad 2, \quad 2
\end{aligned}
$$

The blunt chromosome is one of the two by which ${ }^{b}$ blandina differs from "pale" blandina, namely 8.13 or 9.14 . At present it is not possible to decide which should be assigned to blunt and which to glossy.

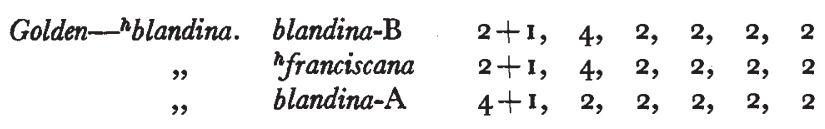

The golden chromosome is one of those by which ${ }^{b}$ blandina differs from blandina-A, namely 3.4 or II.I2. It is one of those in common with blandina-B, and is therefore I I 12 .

\section{(b) Tertiary}

In addition to the primary trisomics, one tertiary (or interchange) trisomic, subwhitish, is known. It has been derived from the interchange blandina-A which possesses chromosomes 3.11 and 4.12 in place of 3.4 and II.I2 (fig. I). The break in chromosome 3.4 is in arm 3 , genetically just proximal to the $\mathrm{P}$ locus and cytologically in the heterochromatic proximal region of the chromosome arm. The break in chromosome $\mathrm{II}_{\mathrm{I}} \mathrm{I}_{2}$ is in arm $\mathrm{I} 2$ in the distal euchromatic region. The result is that chromosome 4.12 is recognisably small 
and unequal armed, the shorter arm being that carrying the translocated segment of arm I 2. The argument leading to the identification of the smaller unequal armed chromosome as 4.12 is dealt with elsewhere (Gatcheside, I953).

Plants trisomic for $4 \cdot 12$ are shorter than diploids, with stiff stems, rather small broadly elliptical leaves which have a slight chlorophyll defect, similar to that of whitish, but obvious only in the seedling and rosette stages. The plants have many of the characters of whitish, but are nearly normally green and much more vigorous. Egg transmission $3^{8}$ per cent.
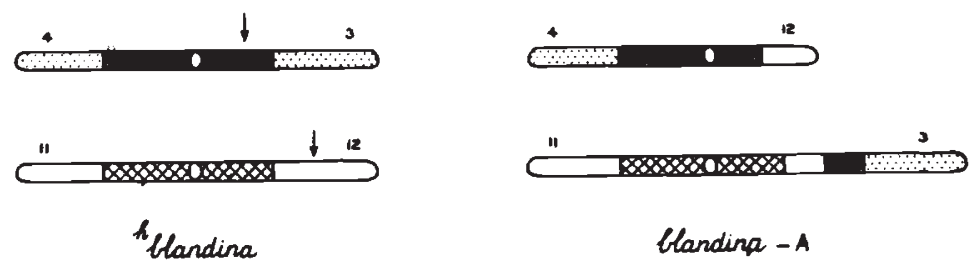

FIG. I.-Diagrams of the chromosome structures differentiating ${ }^{h}$ blandina and blandina- $A$ chromosomes. The black and cross-hatched regions near the centromeres are heterochromatic.

\section{SEGREGATION OF BREVISTYLIS IN PRIMARY TRISOMICS}

Only three of the seven primaries have been included in the test, since stocks of the remaining ones were not available at the time. In each case a normal primary trisomic was pollinated by a diploid brevistylis. The resulting trisomics, each heterozygous for brevistylis, were pollinated by diploid brevistylis and the resulting progenies classified with respect to the distribution of the gene amongst the diploids and the trisomics.

The trisomic whose extra chromosome carried the normal allele of brevistylis would on first crossing by brevistylis give trisomic progeny of constitution $++b r$. Neglecting the effects of crossing over and possible double reduction, the $++b r$ trisomics would give normal gametes in the ratio of $2+:$ I $b r$ and extra chromosome gametes in the ratio of $2+b r: \mathrm{I}++$. Hence the backcross $++b r \times b r b r$ would show amongst the progeny a ratio of $2+$ to I $b r$ amongst the diploids and only + amongst the trisomics.

Each of the remaining kinds of trisomics, whose extra chromosome does not carry the normal allele of brevistylis, would on first crossing by brevistylis give trisomic progeny of constitution $+b r$. These on pollination by $b r b r$ would give equal numbers of + and $b r$ amongst the diploids and the trisomics. In considering the ratios, the diploid and trisomic progeny are taken separately, because the ratio of diploid to trisomic is affected by the reduced viability of gametes giving the latter.

Table I summarises the data obtained in this way. It is clear 
that the blunt and glossy trisomics have shown disomic ratios for $b r$, while the golden trisomic has shown trisomic ratios for $b r$. It would be more satisfactory to have further tests to exclude the remaining chromosomes, nevertheless it is a valid conclusion that $b r$ is situated in chromosome $\mathrm{I} I \cdot I 2$.

TABLE I

Segregation of brevistylis in primary trisonicics

\begin{tabular}{|c|c|c|c|c|c|c|c|}
\hline \multirow[b]{3}{*}{ Heterozygous parent } & \multicolumn{7}{|c|}{ Progeny } \\
\hline & \multicolumn{4}{|c|}{ Diploids } & \multicolumn{3}{|c|}{ Trisomics } \\
\hline & + & $b r$ & $\begin{array}{c}\chi^{2} \\
\text { for } 1\end{array}$ & $\begin{array}{c}x^{2} \\
\text { for } 2: 1\end{array}$ & + & $b r$ & for $\begin{array}{c}x^{2} \\
:\end{array}$ \\
\hline Diploids & $\begin{array}{l}45 \\
50\end{array}$ & $\begin{array}{l}6 \mathrm{I} \\
72\end{array}$ & $\begin{array}{l}\ldots \\
\ldots\end{array}$ & $\begin{array}{l}\ldots \\
\cdots\end{array}$ & $\begin{array}{l}\ldots \\
\ldots\end{array}$ & $\begin{array}{l}\ldots \\
\cdots\end{array}$ & $\begin{array}{l}\cdots \\
\cdots\end{array}$ \\
\hline Totals & 95 & I33 & $6 \cdot 33$ & $\cdots$ & $\cdots$ & $\cdots$ & $\cdots$ \\
\hline Blunt trisomic & $8 \mathrm{I}$ & 77 & 0.101 & $\ldots$ & 44 & $4 \mathrm{I}$ & 0.106 \\
\hline Glossy trisomics & $\begin{array}{l}25 \\
76\end{array}$ & $\begin{array}{l}27 \\
67\end{array}$ & $\begin{array}{l}\ldots \\
\ldots\end{array}$ & $\begin{array}{l}\ldots \\
\ldots\end{array}$ & $\begin{array}{r}7 \\
30\end{array}$ & $\begin{array}{r}8 \\
26\end{array}$ & $\begin{array}{l}\ldots \\
\ldots\end{array}$ \\
\hline Totals & ror & 94 & $0.25 \mathrm{I}$ & $\ldots$ & 37 & 34 & 0.127 \\
\hline Golden trisomics & $\begin{array}{r}34 \\
142 \\
56\end{array}$ & $\begin{array}{l}23 \\
44 \\
23\end{array}$ & $\begin{array}{l}\ldots \\
\ldots \\
\ldots\end{array}$ & $\begin{array}{l}\ldots \\
\ldots \\
\ldots\end{array}$ & $\begin{array}{r}9 \\
37 \\
6\end{array}$ & $\begin{array}{l}\mathbf{0} \\
\mathbf{0} \\
\mathbf{0}\end{array}$ & $\begin{array}{l}\ldots \\
\ldots \\
\ldots\end{array}$ \\
\hline Totals & 232 & 90 & $68 \cdot 8$ & $4 \cdot 2$ & 52 & o & 52 \\
\hline
\end{tabular}

The data are too limited to permit any conclusion as to the probable frequency of double reduction in trisomics. It could affect the frequency of the different genotypes only amongst the trisomic progeny. Most obviously, it would be shown by the appearance of $b r b r b r$ trisomics from the cross $++b r \times b r b r$. It would also be shown by a shift in the ratio of $\mathrm{I}++b r$ to $2+b r b r$ amongst the trisomic progeny such that $+b r b r$ would be relatively less frequent. Where random chromosome segregation predicts $\mathrm{I}++b r$ to $2+b r b r$, random chromatid segregation predicts $6++b r$ to $8+b r b r$ to I $b r b r b r$. Presumably, the actual ratios would lie between these limits.

One of the normal appearing trisomics in the progeny of the golden trisomic was pollinated by br blandina. The resulting family showed 5 normal and $x 6$ brevistylis diploids, but no trisomics. Evidently the parent trisomic was $+b r b r$ and has given the $\mathrm{I}+: 2 b r$ ratio expected amongst its diploid progeny. 


\section{SEGREGATION OF BREVISTYLIS IN THE 4.12 TERTIARY TRISOMIC}

The use of this trisomic allows the determination of whether or not $b r$ is in the segment of arm 12 present in the 4.12 chromosome. If it is not in the distal segment of arm 12, subwhitish trisomics heterozygous for $b r$ will show disomic segregation ratios for the gene amongst diploids and trisomics. If $b r$ is in the distal segment of arm 12, subwhitish trisomics will show trisomic segregation ratios, though these ratios will be different from those encountered in primary trisomics. In fact, the expected kinds of trisomic ratios were observed (table 2), showing that $b r$ is in the distal euchromatic region of chromosome arm I2.

TABLE 2

Segregation of brevistylis in $4 \cdot 12$ tertiary trisomic

\begin{tabular}{|c|c|c|c|c|c|c|}
\hline \multicolumn{3}{|c|}{$\begin{array}{l}\text { Constitution of parental } \\
\text { chromosomes }\end{array}$} & \multicolumn{2}{|c|}{ Diploids } & \multicolumn{2}{|c|}{ Trisomics } \\
\hline $11 \cdot 12$ & $11 \cdot 12$ & $4 \cdot 12$ & + & $b r$ & + & $b r$ \\
\hline+ & $b r$ & + & 36 & $3^{2}$ & 10 & 0 \\
\hline $\begin{array}{l}b r \\
b r \\
b r\end{array}$ & $\begin{array}{l}b r \\
b r \\
b r\end{array}$ & $\begin{array}{l}+ \\
+ \\
+\end{array}$ & $\begin{array}{r}17 \\
10 \\
6\end{array}$ & $\begin{array}{l}78 \\
85 \\
74\end{array}$ & $\begin{array}{l}32 \\
29 \\
29\end{array}$ & $\begin{array}{l}2 \\
8 \\
9\end{array}$ \\
\hline \multicolumn{3}{|c|}{ Totals } & 33 & 237 & 90 & 19 \\
\hline
\end{tabular}

Diploid progeny obtained by pollinating a trisomic by a diploid must receive one of the two $\mathrm{I} \cdot 12$ chromosomes present in the trisomic parent. Trisomic progeny must receive the 4.12 chromosome together with one of the II $\cdot 12$ chromosomes.

When a subwhitish trisomic, homozygous for $\mathrm{br}^{+}$, is pollinated by a $b r$ diploid the trisomic progeny would have one $\mathrm{I} I \cdot \mathrm{I} 2$ chromosome with $b r$ and the other with $b r^{+}$, while the $4 \cdot 12$ chromosome would have $b r^{+}$. Neglecting for the present the effects of crossing-over, such a duplex tertiary trisomic would produce $b r$ and $b r^{+}$haploid gametes in equal numbers, while its extra chromosome gametes would be equal numbers of I I $\cdot 12 b r+4 \cdot 12 b r^{+}$and I I $\cdot 12 b r^{+}+4 \cdot 12 b r^{+}$. Hence pollinating a duplex tertiary trisomic with a $b r$ diploid should yield progeny in which the diploids show equal numbers of $b r$ and $b r^{+}$individuals, while the trisomics should all be $b^{+}$in phenotype. The single progeny of this pedigree in table 2 shows this trisomic type of segregation, but the number of trisomic progeny is rather too small for complete assurance. On the assumption that the $b r$ 
locus is in the 12 segment of chromosome 4.12 , the trisomics in the above progeny should be of two kinds, one being I I $12 b r+I_{1} \cdot I_{2} b r++$ $4 \cdot 12 b r^{+}$and the other II $12 b r+I I \cdot I 2 b r+4 \cdot 12 b r^{+}$. The former should behave like the parental duplex tertiary trisomic, while the latter, a simplex tertiary trisomic, should behave differently. Neglecting crossing over of the $b r$ genes, it would produce haploid gametes

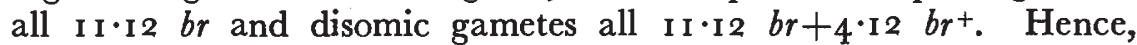
after pollinating by a $b r$ diploid, the progeny should show all diploids $b r$ and all trisomics $b r^{+}$. Tests of three progeny trisomics of the duplex tertiary showed they were all of simplex constitution, since they gave ratios approximating to this expectation, but showing a small proportion (12.25 per cent.) of $b r^{+}$amongst the diploids and a similar small proportion ( 17.5 per cent.) of $b r$ amongst the trisomics.

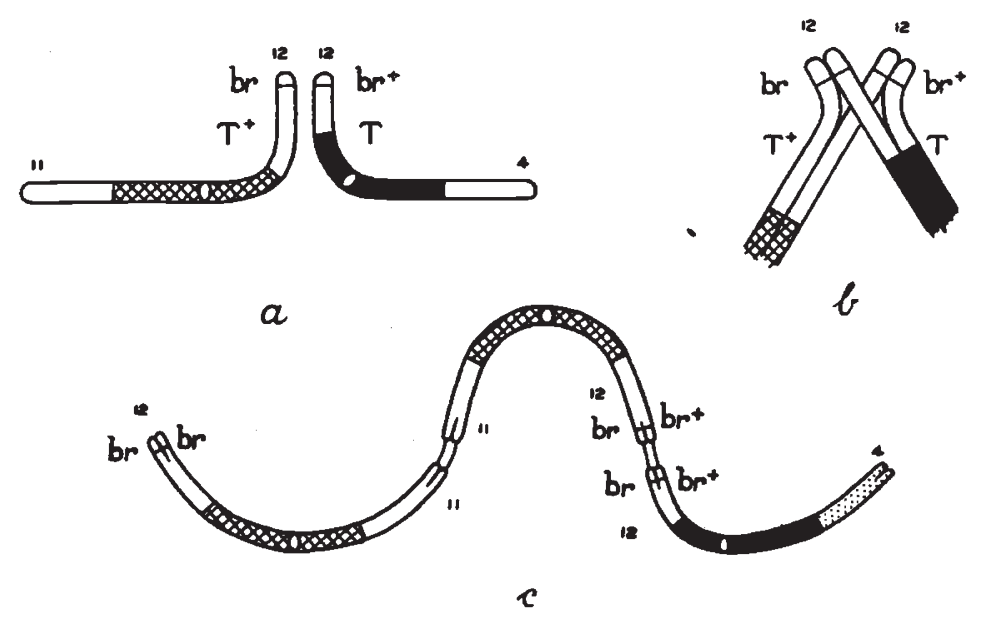

FIG. 2.-Pairing of a $4 \cdot 12$ chromosome with one of the $11 \cdot 12$ chromosomes in the tertiary trisomic, to show the origin of recombinations involving the $b r$ locus ; (a) pachytene, (b) diplotene, (c) metaphase I.

The non-brevistylis diploid individuals represent cases in which $b^{+}$has crossed over into the II 12 chromosome, while the brevistylis individuals amongst the trisomics represent cases in which $b r$ has crossed over into chromosome $4^{\cdot 12}$. Crossovers between the two I I I 2 chromosomes are not detectable. The two sorts of recombinant should be in equal proportion; a contingency test gives a $\chi^{2}$ of $\mathrm{I} \cdot 87$ for one degree of freedom, indicating agreement with the hypothesis of equality. The recombination value, for the interval between $b r$ and the interchange point in $4 \cdot 12$, calculated from the simplex data, is $13 \cdot 7^{2} \pm 1 \cdot 77$ per cent.

The section of chromosome concerned is that bounded distally by the locus of $b r$ and proximally by the place where the translocated fragment of arm 12 is attached to the stump of arm 3 ( $T$ of fig. 2). Presumably chromosome pairing at pachytene is two-by-two, the third chromosome in a trisomic being left out of partnership over a 
given interval in a particular cell. Thus, ignoring changes of partnership within the T-br intercept, pairing of the terminal segment of $4 \cdot 12$ with its homologue in one of the II 12 chromosomes (fig. 2a), followed by chiasma formation (fig. $2 b$ ) and chiasma terminalisation, would yield the chain trivalent shown in fig. $2 c$. The other, larger, segment of chromosome 4.12 would be capable of pairing with the homologous segment of either of the 3.4 chromosomes so that several different chromosome configurations would result at meiosis.

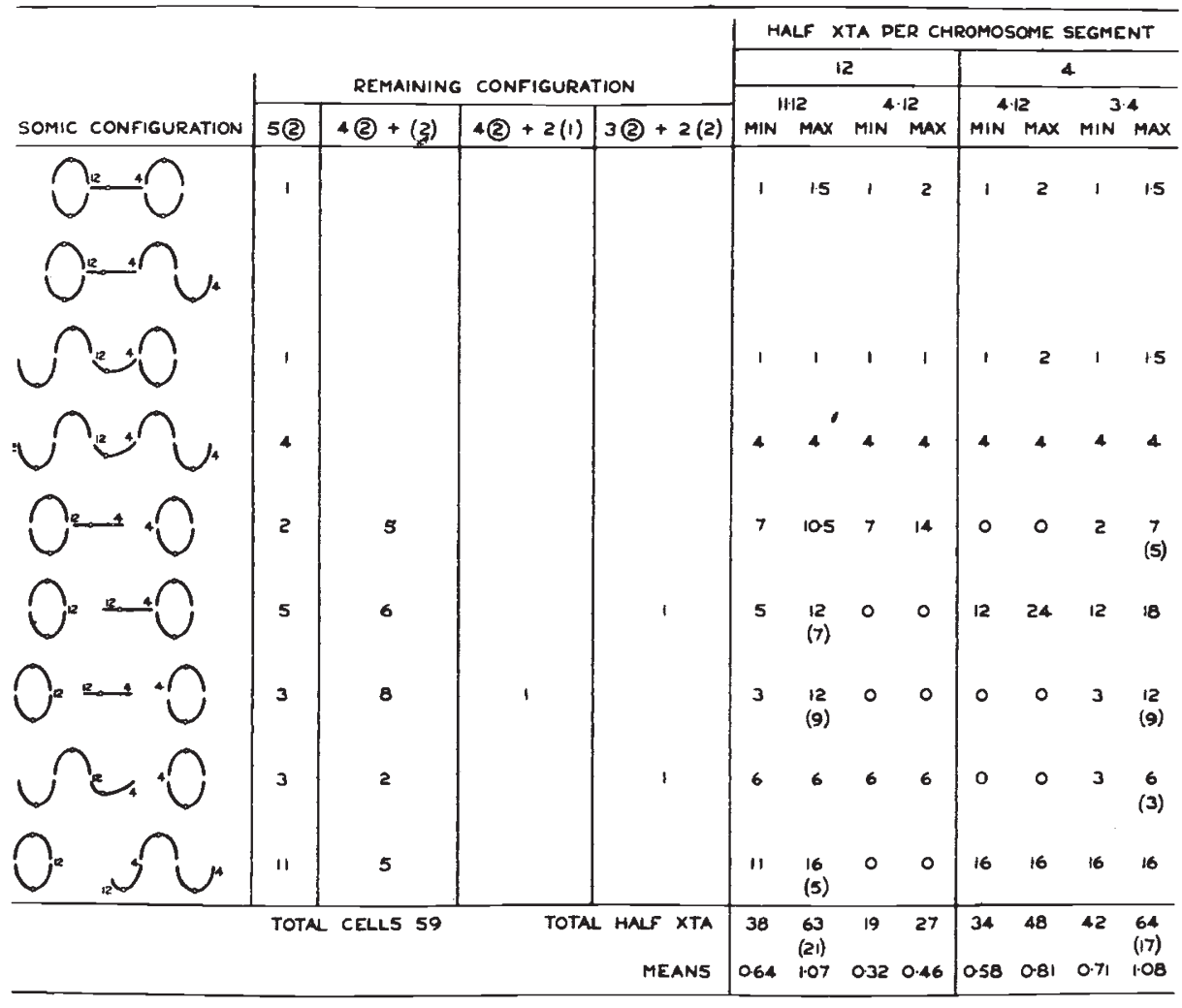

Fig. 3.-Chromosome associations in the tertiary trisomic, their observed frequency, and the inferred half-chiasma frequencies in the trisomic segments.

The nature of these and their observed frequencies are shown in fig. 3. From these data it is possible to obtain approximate estimates of the frequency of half-chiasmata in segments 12 and 4. Uncertainties arise from two circumstances, one being that rod bivalents in certain cases may replace ring bivalents in the trisomic configuration; the maximum possible number of these is shown in brackets in the figure. The other is that where a triple (terminal) chiasma occurs, the assignment of two of the half-chiasmata to the three possible chromosomes is arbitrary. The figures obtained therefore represent minimal and maximal estimates from the data. There is some indication of 
preferential association of the 3.4 chromosomes with one another, but it is probably not very strong.

The frequency of chiasma formation between 4.12 and an II.I2 chromosome is between $0.3^{2}$ and 0.46 per cell. The genetic length of the translocated 12 segment, measured cytologically as half the chiasma frequency, is therefore about 16 to 23 units. This is not much greater than the amount of recombination observed in the tertiary trisomic and indicates that the $b r$ locus is very close to the distal end of chromosome arm 12.

The recombination value measured above is not an ordinary one, since it represents only the frequency with which a gene at the $b r$ locus in chromosome $4^{\cdot} \mathrm{I} 2$ recombines with a gene at the $b r$ locus in either of the two II.I2 chromosomes with which it may associate in the tertiary trisomic: It does not measure recombination between the two II'I2 chromosomes, which must also occur within the same interval.

TABLE 3

Expected segregations of brevistylis in 4.12 tertiary trisomics

\begin{tabular}{|c|c|c|c|c|c|c|c|c|c|c|}
\hline \multirow{2}{*}{\multicolumn{3}{|c|}{$\begin{array}{l}\text { Trisomic } \\
\text { constitution }\end{array}$}} & \multicolumn{4}{|c|}{ General formulæ } & \multicolumn{4}{|c|}{ Values for $a=0.14$} \\
\hline & & & \multicolumn{2}{|c|}{ Diploids } & \multicolumn{2}{|c|}{ Trisomics } & \multicolumn{2}{|c|}{ Diploids } & \multicolumn{2}{|c|}{ Trisomics } \\
\hline $11 \cdot 12$ & $11 \cdot 12$ & $4 \cdot 12$ & + & $b r$ & + & $b r$ & + & $b r$ & + & $b r$ \\
\hline+ & + & $b r$ & $\mathrm{I}-a$ & $a$ & $\frac{4-a}{4}$ & $\frac{a}{4}$ & 0.86 & 0.14 & 0.965 & 0.035 \\
\hline+ & $b r$ & + & $\mathbf{I}+a$ & $\mathrm{I}-a$ & $2-a$ & $\frac{a}{a}$ & 0.57 & 0.43 & 0.93 & 0.07 \\
\hline & & & $\stackrel{2}{1}-a$ & $\stackrel{2}{1+a}$ & $\begin{array}{l}2 \\
a\end{array}$ & $2 \stackrel{2}{2-a}$ & & & & \\
\hline+ & $b r$ & $b r$ & 2 & $\frac{1}{2}$ & 2 & 2 & 0.43 & 0.57 & 0.07 & 0.93 \\
\hline$b r$ & $b r$ & + & $a$ & $1-a$ & $\mathrm{I}-a$ & $a$ & 0.14 & $0 \cdot 86$ & 0.86 & $0 \cdot 14$ \\
\hline
\end{tabular}

If it may be assumed that the two II I 2 chromosomes do not pair with one another preferentially, but rather that, with respect to the T- $b r$ interval, they and chromosome 4.12 pair at random, the true recombination value would be half as great again as the apparent one, namely be 20.58 per cent. In so far as there was any preferential pairing of the two II.I2 chromosomes with one another, the true value would be even greater. No method is immediately available by which such preferential pairing and recombination could be measured.

There are four possible kinds of heterozygote in a tertiary trisomic and each yields a different ratio amongst its diploid and trisomic progeny, when pollinated by diploid brevistylis. Taking $a$ as the apparent recombination, namely the total recombination between the 4.12 and $\mathrm{II} \cdot 12$ chromosomes, the theoretical proportions of brevistylis given in table 3 may be calculated. The actual values, for the case $a=0 \cdot 14$, are also given. 


\section{SEGREGATION OF BREVISTYLIS IN AN INTERCHANGE HETEROZYGOTE}

The interchange heterozygote (figs. I and 4), from which the tertiary trisomic was obtained, provides an opportunity to see whether brevistylis shows pseudolinkage with genes on other chromosomes in the interchange. Only one segregating family, capable of showing this, has so far been examined. The heterozygote had $P^{r} b r^{+}$in the

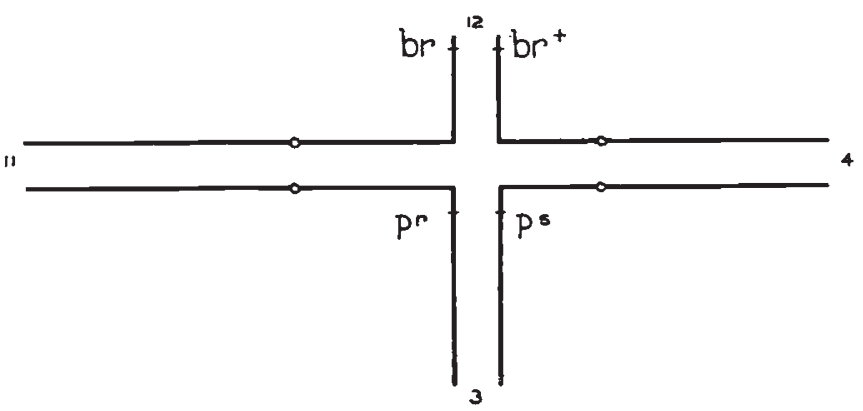

Fig. 4. $\rightarrow$ Diagram of pachytene pairing in interchange heterozygote, to show the relations of the $b r$ and $P$ loci.

interchange (blandina-A) and $P^{s} b r$ in the normal ('blandina) chromosomes. It was pollinated by a homozygous $P^{s} b r$ normal plant. The progeny are recorded in table 4 . The means of classifying the interchange and normal plants are those previously described (Catcheside, 1947).

TABLE 4

Progeny of $\frac{A P^{r}+}{+P^{s} b r} \times \frac{+P^{s} b r}{+P^{s} b r}$

\begin{tabular}{|c|c|c|c|c|c|}
\hline & \multicolumn{2}{|c|}{$P^{r}$} & \multicolumn{2}{|c|}{$P^{*}$} & \multirow{2}{*}{ Totals } \\
\cline { 2 - 5 } & + & $b r$ & + & $b r$ & \\
\hline$A$ & 56 & 7 & 0 & 0 & 63 \\
+ & 2 & 0 & 13 & 64 & 79 \\
\cline { 2 - 5 } Totals & $5^{8}$ & 7 & $1_{3}$ & 64 & 142 \\
\hline
\end{tabular}

The non-recombinant classes are $A P^{r}+$ and $+P^{s} b r$ and total 120. Recombinants in interval $\mathrm{I}$, between the $P$ locus and the interchange locus, would be $A P^{s}+$ and $+P^{r} b r$; none were present. Recombinants in interval 2, between the interchange locus and the $b r$ locus, are $A P^{r} b r$ and $+P^{s}+$, totalling 20. Double recombinants in intervals $I$ and 2 simultaneously, would be $+P^{r}+$ and $A P^{s} b r$; 
2 were found. Formally the recombination value in interval $I$ is $I \cdot 4$ per cent. (2/142) and in interval 2 is $14.8 \pm 3.04$ per cent. (22/142). The data are peculiar in showing 2 double recombinants when there were no singles in interval $I$. The conclusion they suggest, that the $P$ locus is between the interchange and $b r$ loci, is not consistent with other far stronger evidence (Catcheside, I953) which points to the relationship shown in fig. 3 , nor with abundant previous work which has shown the $P$ locus to be in chromosome arm 3 .

The observed chiasma frequency between the $4 \cdot 12$ and II I 2 chromosomes in the interchange heterozygote is about 0.28 per cell, indicating the genetic length of the translocated 12 segment is about I 4 units. This is consistent with the $b r$ locus being very close to the distal end of arm 12. The recombination value, for the $b r$ to interchange interval, in the interchange heterozygote, is not significantly different from the apparent value found in the tertiary trisomic. Nor is it different significantly from the "corrected "value in the tertiary trisomic, obtained on the assumption of no preferential pairing of the two II.I2 chromosomes with one another. The data are not consistent with the occurrence of any appreciable preferential pairing of this segment in the tertiary trisomic. Random pairing would be expected if zygotene association of the chromosomes began at the ends of the chromosomes, a conclusion suggested also by other lines of evidence, such as the frequent interlocking of bivalents at meiosis in Enothera.

\section{NON-DISJUNCTIONAL GAMETES AND THE BREVISTYLIS LOCUS}

The interchange heterozygote, $3 \cdot 4+4 \cdot 12+12 \cdot I I+I I \cdot 3$, produces predominantly the two kinds of disjunctional gamete $3 \cdot 4+\mathrm{II} \cdot \mathrm{I} 2$ and $3 \cdot$ I I $+4 \cdot$ I 2. It also produces, very occasionally, two kinds of viable non-disjunctional gamete, $3 \cdot 4+3 \cdot I$ I and II I $2+4 \cdot I 2$, through adjacent chromosomes of the interchange ring passing to the same spindle pole at anaphase I of meiosis. The former has been called $A-D p$ and the latter $A-D f$ (Catcheside, I947), because the $P$ and $s$ loci are duplicated and missing respectively in the two kinds of gamete. This interpretation corrects a previous error in the understanding of $A-D p$ and $A-D f$ and is fully discussed elsewhere (Catcheside, I953). The gamete $A-D p$ lacks the distal segment of arm 12, while $A-D f$ has it duplicated. If the placing of the $b r$ locus in the distal region of arm 12 is correct, a zygote composed of $A-D p$ and a normal gamete bearing the gene $b r$ should have the brevistylis phenotype, whereas a corresponding $A-D f$ zygote should not. Several families containing plants of these constitutions have been grown and in each case the $A-D p$ and $A-D f$ plants had the expected phenotypes with respect to brevistylis. The numbers of plants observed though not large, namely four of each type, are highly significant because the 
cross in each case was of the type $\frac{A+}{++} \times \frac{+b r}{+b r}$, the brevistylis gene coming only from the male parent.

\section{SUMMARY}

Primary trisomic segregation tests in Enothera blandina show that the brevistylis locus is in chromosome II I2. A tertiary (or interchange) trisomic segregation test places the locus very close to the distal end of arm I2. The constitutions of non-disjunctional gametes from an interchange heterozygote support this conclusion.

This is the first demonstration that a gene which shows free recombination with the differential segments in a complex heterozygote is located in the distal part of a chromosome. The location in the end of a chromosome, which is a pairing segment, with a probable mean of at least one chiasma in meiotic cells, accounts for the segregation being independent of that of the differential segments.

\section{BIBLIOGRAPHY}

CAtcheside, D. G. 1937. The extra chromosome of Enothera Lamarckiana lata. Genetics, 22, 564-576.

CAtGheside, D. G. I940. Structural analysis of Enothera complexes. P.R.S., B, $128,509-535$.

Gatcheside, D. G. 1947. The P-locus position effect in Enothera. 7. Genet., 48, $3 I-42$.

GAtcheside, D. G. I953. Non-disjunction in an Enothera interchange heterozygote. $\mathcal{F}$. Genet. (In the press.)

EMERSON, S. H., AND STURTEVANT, A. H. 1932. The linkage relations of certain genes in Enothera. Genetics, 17, 393-412.

RENNER, O. 1942. Über das crossing-over bei Enothera. Flora, N.S., 36, 117-2 I 4 . DE VRIES, H. I9OI-03. Die Mutations Theorie. Leipzig. 